Running head: LONGITUDINAL CHANGES IN ATTACHMENT

\title{
Longitudinal Changes in Attachment Orientation over a 59-year Period
}

\author{
William J. Chopik \\ Michigan State University \\ Robin S. Edelstein \\ University of Michigan \\ Kevin J. Grimm \\ University of California, Davis
}

In press at Journal of Personality and Social Psychology

\section{Author Note}

William J. Chopik, Department of Psychology, Michigan State University, East Lansing. Robin S. Edelstein, Department of Psychology, University of Michigan, Ann Arbor. Kevin J. Grimm, Department of Psychology, University of California, Davis, CA.

Correspondence concerning this manuscript should be addressed to William J. Chopik, Department of Psychology, Michigan State University, 316 Physics Rd., East Lansing, Michigan 48824. E-mail: chopikwi@msu.edu 


\begin{abstract}
Research on individual differences in attachment - and their links to emotion, cognition, and behavior in close relationships — has proliferated over the last several decades. However, the majority of this research has focused on children and young adults. Little is known about meanlevel changes in attachment orientation beyond early life, in part due to a dearth of longitudinal data on attachment across the lifespan. The current study used a Q-Sort-based measure of attachment to examine mean-level changes in attachment orientation from age 13 to 72 using data from the Block and Block Longitudinal Study, the Intergenerational Studies, and the Radcliffe College Class of 1964 Sample (total $N=628$ ). Multi-level modeling was employed to estimate growth curve trajectories across the combined samples. We found that attachment anxiety declined on average with age, particularly during middle age and older adulthood. Attachment avoidance decreased in a linear fashion across the lifespan. Being in a relationship predicted lower levels anxiety and avoidance across adulthood. Men were higher in attachment avoidance at each point in the lifespan. Taken together, these findings provide much-needed insight into how attachment orientations change over long stretches of time. We conclude with a discussion about the challenges of studying attachment dynamics across the life course and across specific transitions.

Keywords: attachment, personality development, lifespan development, anxiety, avoidance
\end{abstract}




\section{Longitudinal Changes in Attachment Orientation over a 59-year Period}

Attachment theory was originally conceptualized by John Bowlby (1969/1982) as a developmental model in which relationship processes unfold across a person's lifespan, influencing us "from the cradle to the grave" (p. 208). Indeed, there are many important links between attachment orientation and emotion, cognition, and behavior in close relationships (Cassidy \& Shaver, 2008). Yet the majority of this work has focused on early childhood and young adulthood. How do attachment orientations change across the lifespan? Unfortunately, despite the many significant relationship-relevant life events that occur in middle and older adulthood that might affect attachment orientations, this critical question has eluded researchers (Magai, 2008).

Attachment orientations, or individuals' characteristic approaches to close relationships, are thought to be forged during initial interactions with caregivers but are nevertheless susceptible to change over time and across relationships (Bowlby, 1980). Thus, a lifespan perspective can provide a valuable framework for attachment research. Yet the few attempts to describe age-related differences in attachment thus far have been cross-sectional in nature (Chopik \& Edelstein, 2014; Chopik, Edelstein, \& Fraley, 2013). Although cross-sectional data are important for providing broad, descriptive patterns, the interpretations from these data are often unclear-do age differences reflect how people change across the lifespan? Or do these differences reflect differences between people who are members of different birth cohorts? Unfortunately, longitudinal data, which are critical for addressing this question, are lacking.

The goal of the current study was to examine longitudinal mean-level changes in an individual's attachment orientation from age 13 to age 72 using five archival data sets on human development. Collectively, the data sets comprise 628 individuals, born over 47-year period 
(from 1920 to 1967$)$ and followed over 59 years in varying intervals across 21 assessments $(N=$ 1,940 total observations). A newly developed measure of attachment orientation using the California Q-Sort (Chopik \& Edelstein, 2015) was employed to track mean-level changes in attachment across the lifespan. We also examined whether relationship status predicted meanlevel changes in attachment.

In the following sections, we review the existing evidence regarding lifespan differences in attachment orientation and the mechanisms that might drive mean-level changes in attachment orientation.

\section{Developmental Changes in Attachment Orientation}

An individual's attachment orientation is defined as their position on two dimensions: attachment anxiety and attachment avoidance (Fraley \& Waller, 1998). Attachment-related anxiety reflects concerns about the availability and accessibility of close others (Mikulincer, Gillath, \& Shaver, 2002). Attachment anxiety is associated with a hypervigilance about abandonment and rejection and excessive reassurance-seeking (Fraley et al., 2006; Shaver, Schachner, \& Mikulincer, 2005). Attachment avoidance reflects a discomfort with emotional and physical intimacy and efforts to suppress emotional experiences and expressions (Edelstein \& Shaver, 2004; Fraley, Davis, \& Shaver, 1998). Attachment avoidance is associated with difficulties providing emotional support for romantic partners and negative views toward intimate touch (Brennan, Clark, \& Shaver, 1998; Chopik, Edelstein, et al., 2014; Li \& Chan, 2012). Individuals low in anxiety and avoidance are considered secure.

Roberts and colleagues (2005) suggest that making commitments to and investing in social institutions are mechanisms that facilitate personality change over time. These institutions, often conceptualized as social roles (e.g., partnership, parenting) are normative, often occur 
during specific life stages, and are accompanied by an expectation of social maturity (Roberts et al., 2005). Across the lifespan, people invest in different types of relationships, and these interactions with relationship partners likely change how people approach close relationships more generally. Several relationship milestones also occur during a particular life stage or age, and by examining how attachment orientations change across the lifespan, researchers can better understand how individuals tend to approach relationships at different life stages.

Based on the idea that investment in close relationships can change psychological characteristics, one can make specific predictions about how attachment anxiety might change over time. For example, investing in close relationships has the potential to decrease anxiety. Close relationships likely facilitate and demand increases in emotion regulation, which may lead to decreases in negative emotionality and thus attachment anxiety (e.g., Gross et al., 1997). Indeed, there is some support for the hypothesis that older adults would be lower in attachment anxiety compared to younger adults (Diehl et al., 1998). In an initial cross-sectional study of age differences in attachment orientation (Chopik et al., 2013), we examined age differences in attachment orientation as a function of relationship status and gender in a sample of 86,555 participants that included middle-aged and older adults. Our findings revealed that attachment anxiety was highest among younger adults and lowest among middle-aged and older adults, suggesting that emotion regulation may indeed increase across the lifespan. These age differences were replicated in an independent sample of over 90,000 participants from 81 different countries (Chopik \& Edelstein, 2014). Similar trends are also found when people are asked about their attachment orientations with specific people (Hudson et al., 2015). The one long-term longitudinal study of changes in attachment anxiety shows similar trends as those found in cross-sectional studies, with attachment anxiety declining in women from age 27 to 52 
(Klohnen \& John, 1998). However, to our knowledge, there is no study documenting the trajectory of attachment anxiety from adolescence into young adulthood and beyond.

Transitions in life roles may also have implications for how attachment avoidance changes with age, although the evidence for age-related changes in avoidance is more mixed. Adolescents and young adults begin to explore their identities and develop more independence and autonomy as they approach their mid-twenties (Erikson, 1968; Whitbourne \& Tesch, 1985). As adolescents transition toward adulthood, these individuation processes trigger a shift of attachment needs from parents to peers and romantic partners (Fraley \& Davis, 1997). As a result of these higher levels of independence and autonomy, individuals might become more selfreliant, which is a defining characteristic of attachment avoidance (Wardecker et al., 2017). Because individuation processes are heightened among adolescents and young adults, avoidance might be highest during these life stages. However, in older adulthood, individuals' attention and effort is more focused on maintaining close relationships, which could be reflected in lower levels of avoidance (Carstensen, Isaacowitz, \& Charles, 1999). Thus, avoidance may show less mean-level change across the lifespan but decline into older adulthood.

Although there are some theoretical reasons to expect that attachment avoidance might decline across the lifespan, this association might not be straightforward (Mickelson, Kessler, \& Shaver, 1997). Several studies with large age ranges find that avoidance is positively correlated with age (e.g., Birnbaum, 2007). Other studies show either no relationship or inconsistent relationships with age (e.g., Noftle \& Shaver, 2006). In the aforementioned large study of age differences, attachment avoidance showed less dramatic age differences (compared to anxiety), but was higher in middle-aged adults and lower in younger and older adults (Chopik, Edelstein, \& Fraley, 2013). These cross-sectional patterns also replicate in several different cultures and 
across relationships (Chopik \& Edelstein, 2014; Hudson et al., 2015). However, one of the few longitudinal studies to date provides little evidence for mean-level changes in avoidance in women from young to middle adulthood (Klohnen \& John, 1998). As with anxiety, there is little work examining the trajectories of avoidance through adolescence and into adulthood.

Unfortunately, given that most of the work on age-related differences in attachment is cross-sectional (Fraley, 2002; Zhang \& Labouvie-Vief, 2004), it is impossible to know whether age differences in attachment orientation result from developmental processes (Klohnen \& John, 1998) or pre-existing differences between birth cohorts (Konrath et al., 2013; Magai et al., 2001). For example, higher levels of attachment anxiety among younger adults could be specific to members of a particular birth cohort (i.e., those born in the 2000s). Likewise, lower levels of attachment anxiety among middle aged and older adults could be specific to members of a different birth cohort (i.e., those born in the 1970s or earlier). Thus, age differences in attachment would not reflect a developmental process (e.g., increases in emotion regulation skills over time), but rather static differences in psychological characteristics of birth cohorts that arise from the different sociocultural norms to which they are exposed. The universality of age differences in attachment across cultures somewhat alleviates this concern, by showing that attachment develops in a similar way across different sociocultural contexts (Chopik \& Edelstein, 2014). Nevertheless, longitudinal data remain the gold standard for understanding developmental changes in attachment orientation.

\section{The Moderating Role of Relationship Status}

Relationships can influence people in important ways. For instance, social norms and romantic partners reward appropriate behavior and admonish inappropriate behavior (Roberts et al., 2005). By investing in these social roles, individuals adhere to the rules and appropriate 
behavior of close relationships and may change how they approach relationships accordingly, perhaps becoming more secure. Indeed, partnered individuals often report lower levels of anxiety and avoidance compared to single individuals (e.g., Edelstein \& Gillath, 2008). This pattern of findings may be attributable to close relationships increasing attachment security (Kirkpatrick \& Hazan, 1994). However, prospective data on relationship status and mean-level changes in attachment orientations are rare. With age, relationships become increasingly more central to development and functioning and individuals shift their efforts toward forging and preserving close, meaningful relationships (Carstensen et al., 1999). Thus, people in relationships may experience greater increases in attachment security across the lifespan.

Consistent with this premise, attachment security generally increases over the first few years of marriage (Davila, Karney, \& Bradbury, 1999). These increases in security are attributable to increases in the perceived stability of the relationship and the security-enhancing functions that spouses enact to promote closeness. Attachment orientation predicts relationship initiation as well, as avoidant individuals are less likely to transition from casual to committed relationships (Schindler, Fagundes, \& Murdock, 2010). These findings suggest that when people are in relationships, they should have lower levels of anxiety and avoidance than when they are single.

In the aforementioned cross-sectional study of age differences in attachment, people in relationships were indeed lower in anxiety and avoidance at every point in the adult lifespan (Chopik et al., 2013). Further, associations between avoidance and relationship status were stronger in middle adulthood compared to young adulthood. Although previous research suggests that relationship status may have security-enhancing effects on people across the lifespan, the short time frame of existing longitudinal studies and the cross-sectional nature of most data limit 
our ability to make definitive statements about mean-level changes over time. Does relationship status exert a static influence on attachment over time (Davila et al., 1999) or do relationships enhance security primarily during particular developmental periods (Chopik et al., 2013; Chopik, Moors, \& Edelstein, 2014)? We examined this question by examining the degree to which changes in relationship status moderated age-related changes in attachment orientation across the lifespan.

\section{The Current Study}

We made several hypotheses about changes in attachment across the lifespan based on cross-sectional and longitudinal evidence of age-related differences in attachment orientation. First, we predicted that attachment anxiety would be highest in adolescence and young adulthood before decreasing across the lifespan. Second, we predicted that attachment avoidance would show less dramatic mean-level changes across the lifespan, but would generally decline in older adulthood. Finally, we expected that when in relationships, individuals would be higher in security (i.e., lower anxiety and avoidance) and become more secure over time compared to when they are single. In the current report, we focus our attention on mean-level changes in attachment orientation given the lack of such data currently available in the literature, rather than rank-order stability over time. Nevertheless, we report the average rank-order stability of anxiety and avoidance in our current data (see Fraley, 2007; Fraley \& Roisman, 2015; Fraley, Roisman, \& Haltigan, 2013; Fraley et al., 2011; for extensive discussions and examinations regarding the rank-order stability of attachent over shorter intervals of time).

To examine these hypotheses, we assessed mean-level changes in attachment orientation using five longitudinal data sets, each of which spans from 9 years for the shortest study to 47 years for the longest study. Each study included the California Q-Sort, a broad, card-sorting 
measure of personality, throughout the data collection. The California Q-Sorts were implemented independently by different research teams. A Q-Sort-based measure of attachment orientation was constructed using expert ratings and a validation sample of self- and observer-reported measures (see Chopik \& Edelstein, 2015, and below for more details). We used this measure to assess attachment orientation from existing Q-Sort data from the five longitudinal studies from age 13 to 72 .

\section{Method}

The current study includes data from multiple widely used data sets (i.e., the Block and Block Longitudinal Study of Cognitive and Ego Development, the Intergenerational Studies, the Radcliffe College Class of 1964 study). Many papers have been published using the personality data from these samples (Block, 1971; Block \& Block, 2006; Eichorn et al., 1981; Haan, Millsap, \& Hartka, 1986; Stewart \& Vandewater, 1993). However, the current analyses do not overlap with this past research with respect to mean-level changes in attachment orientation, with one exception: The examination of mean-level changes in attachment from ages 14 through 23 in the Block and Block Longitudinal Study as a function of early caregiving environments (Chopik, Moors, et al., 2014). Thus, portions of the data have been published elsewhere but have not been used in integrative analyses like the ones reported below. Because the study utilized existing data sources, it was considered exempt from oversight of an ethics review board. ${ }^{1}$

\section{Participants}

\section{Block and Block Longitudinal Study of Cognitive and Ego Development. One}

hundred and seven individuals $(50.5 \%$ female, $47.1 \%$ partnered at age 18$)$ were participants in the Block and Block Longitudinal Study of Cognitive and Ego Development, which was initiated in 1968 at the University of California at Berkeley (for full description, see Block \& Block, 
2006). The sample was recruited from two preschools in Berkeley, California. Q-Sort measures were collected at ages 14,18 , and 23 . The ethnic composition of the sample was $68.3 \%$ Caucasian, 24\% African-American, 4.8\% Asian-American, and 2.9\% other ethnicities.

Intergenerational Studies. Three hundred and fifty four individuals (53.7\% female; $90.5 \%$ partnered at first adult wave [ ages 30-40]) were participants in the Intergenerational Studies, an umbrella study combining participants from the Berkeley Guidance Study $(N=171)$, the Oakland Growth Study $(N=121)$, and the Berkeley Growth Study $(N=62)$. The three longitudinal studies were started in the late 1920s and early 1930s and continued for over 70 years. The Berkeley Guidance and Growth Studies sampled infants born in the Berkley area in 1928-1929. The Oakland Growth Study began in 1932 and sampled fifth and sixth graders (approximate birth year $=1921)$. Frequency of Q-Sort assessments was high in each study: Berkeley Guidance (ages 13, 16, 30, 40, 52), Oakland Growth (ages 13, 16, 40, 50, 60), and Berkeley Growth (ages 13, 16, 36, 52), respectively. Eighty-eight percent of participants were married at the first wave of each study when this information was first collected (age 30 and later). All participants from the Berkeley Growth and Oakland Growth Study were Caucasian; a small percentage of participants from the Guidance Study were African American (3\%). Socioeconomic status was similar across the three samples: Forty percent of Oakland Guidance Study participants and $33 \%$ of participants from the remaining two samples came from households classified as working-class; the remaining participants were from upper-class households. The Intergenerational Studies are considered landmark studies in human development; their history and sampling have been extensively documented elsewhere (Block, 1971; Eichorn et al., 1981; Haan et al., 1986).

Radcliffe College Class of 1964. One hundred and sixty seven individuals (all female, 
43.7\% partnered at age 43) were participants in a longitudinal study of members of the 1964 graduating class of Radcliffe College (see Stewart \& Vandewater, 1993, for full description). Qsort measures were collected at ages 43, 53, 62, and 72. All but one woman was European American. Eighty percent of the sample had completed at least some graduate-level education.

Combined Sample. Sample sizes at each assessment wave, study design, and the number and timing of assessment points are presented in Table 1. The average age of the combined sample, across assessment waves, was 38.80 years $(S D=18.58 ; 65 \%$ female; $67.9 \%$ partnered at the first wave at which relationship status information was collected). A substantial portion of the combined sample changed relationship status over each study ( $20 \%$ in each sample) and this is modeled in the moderation analyses below. A series of supplementary analyses examined the role of education (a z-scored index of education created within each sample) on mean-level changes in attachment orientation. These supplementary analyses suggested that the results reported below are largely independent of education with respect to both main effects $(p s>.15)$ and interactions with time $(p s>.35)$. Unfortunately, income data were not reliably available across the samples.

\section{Measures}

Attachment Orientation. At each wave, attachment orientation was assessed using items from the California Adult Q-Sort (CAQ; Block, 1961, 2008). The CAQ is a broad personality measure comprised of 100 descriptive items. These 100 items are sorted using a forced distribution into nine categories, ranging from 1 (extremely uncharacteristic) to 9 (extremely characteristic). Evaluations were completed by study personnel, who included clinicians, graduate students, and psychologists. The basis of the evaluations were in-depth interviews and observations conducted during a variety of experimental tasks. Q-Sorts from multiple observers 
were averaged within each participant at each assessment wave. Scales for anxiety and avoidance were created from these averaged composites. Attachment orientation measures assessed through the CAQ were previously developed and validated in a separate sample of participants created in consultation with expert ratings (see Chopik \& Edelstein, 2015; for full details).

In this validation study, five experts familiar with attachment theory rated each of the 100 items in the CAQ with respect to how much each item characterized anxiety and avoidance, respectively. The top 14 rated items for both anxiety and avoidance were chosen to comprise scales for attachment orientation. No items overlapped between anxiety and avoidance. In a validation sample, a group of observers filled out the CAQ and an observer-based version of a widely used attachment measure (Brennan et al., 1998). The targets of these judgments were also contacted and given self-report measures of attachment and personality. We then compared the correspondence of self- and observer- ratings of attachment between the CAQ instrument and the more established attachment measure. The anxiety and avoidance composites from the CAQ correlated highly with other self-report measures of attachment. Sample items include "Seeks reassurance from others" (anxiety) and "Keeps people at a distance; avoids close relationships" (avoidance). Internal consistency of the anxiety and avoidance scales was high at each wave and within each sample $\left(\alpha_{\text {Mean }}=.80\right.$; see Supplementary Table 1 for a full list of alphas for each sample at each wave).

\section{Results}

\section{How do attachment orientations change over time?}

Test-retest (i.e., stability) correlations, correlations between anxiety and avoidance, and descriptive statistics are provided in Table 2. Across all intervals and ages, anxiety $\left(r_{\text {mean }}=.40\right)$ and avoidance $\left(r_{\text {mean }}=.44\right)$ showed moderate levels of stability over time. As the interval 
between two assessment points increased, the stability of anxiety $(\beta=-.58, p<.001)$ and avoidance $(\beta=-.44, p<.001)$ decreased, replicating similar work on other psychological characteristics (e.g., Big Five personality traits; Fraley \& Roberts, 2005). Given that men tended to score higher in avoidance in these preliminary correlations $(r s>.18)$ and in prior work using CAQ measures of attachment orientation (Chopik, Moors, et al., 2014), participant gender was included as a covariate in all analyses.

The five samples were combined for the purposes of multi-level analyses in a variant of an accelerated longitudinal design, in which data sets with overlapping ages are combined to estimate growth curves across the entirety of the data (Helson, Jones, \& Kwan, 2002; Hirschberger et al., 2009; Miyazaki \& Raudenbush, 2000; Raudenbush \& Chan, 1992; Terracciano et al., 2005). The samples were combined because of the similarity and overlap between the samples, to maximize power, and to present the data in the most parsimonious way. Given that smaller intervals of time might not be sufficient to capture the security-enhancing effects of close relationships, combining the data also enabled us to test the long-term moderating effects of changes in relationship status on mean-level changes in attachment. Following the observation that it is more appropriate to examine research questions within one larger sample rather than smaller, separate samples (which sacrifices power and increases the number of false positive findings; see Schimmack, 2012), we present only the results from this larger combined sample. Nevertheless, subsample analyses can be provided upon request from the first author. Sample source was added as a covariate in all the analyses reported below. The Radcliffe Sample (the eldest sample) was added as the reference group against which the other samples were compared. Sample source did not moderate any of the associations between age and attachment orientation. 
This variant of accelerated longitudinal design can assess broader developmental questions (i.e., how does attachment change from age 13 to 72 ?) as well as more specific, cohortsequential questions (i.e., does the attachment orientation of participants born in the late 1920s change at a different rate than the attachment orientation of participants born in the late 1960s?). Below, we focus on the former question and moderators of mean-level changes in attachment from age 13 to 72 .

Age was grand-mean centered based on the mean from the overall combined sample and scaled in terms of decades of life (i.e., (centered age)/10); thus, all age coefficients can be interpreted as the expected increase or decrease in anxiety/avoidance per decade of life (see Hudson et al., 2015; for a similar approach). Worth noting, this transformation does not affect the direction or significance of any effects, but rather aids in interpretation of the effects. Gender was contrast coded $(-1=$ men, $1=$ women $)$ prior to computing the interaction terms and treated as time invariant. Attachment orientation (anxiety, avoidance) was predicted from age, age ${ }^{2}$, gender, and the interaction between these variables.

We hypothesized that anxiety would be higher in adolescence and young adulthood before declining across the lifespan. We also hypothesized that avoidance would show fewer mean-level changes across the lifespan, but would generally decline. To test these hypotheses, we used growth curve modeling in the SPSS Mixed command (Peugh \& Enders, 2005), which enabled us to model intra-individual changes and moderators of these changes (Roberts \& Chapman, 2000; Willett, 1988). Degrees of freedom were computed using the Satterthwaite (1946) method.

Results from the growth curve analyses for anxiety and avoidance are presented in Tables 3 and 4 , respectively. For anxiety, the effects of age, age $^{2}$ and age $\times$ gender emerged as 
significant predictors. As seen in Figure 1a, anxiety was relatively stable throughout adolescence and young adulthood before declining throughout middle age and older adulthood. The effect of age on anxiety was moderated by gender such that men showed more dramatic declines in anxiety $(b=-.16, S E=.03, t(694.31)=-4.97, p<.001)$ compared to women $(b=-.05, S E=.02$, $t(917.69)=-2.56, p=.01)$. For avoidance, only the effects of age and gender emerged as significant predictors. As seen in Figure 1b, avoidance declined in a linear fashion across the lifespan. Men were higher in avoidance overall.

\section{Does relationship status moderate changes in attachment orientation in adulthood?}

To test moderation, we ran separate growth curve models that included relationship status as a time-varying moderator of mean-level changes in attachment orientation. Age (ages 18 through 72) and relationship status ( $-1=$ single, $1=$ partnered $)$ at the adult assessments were treated as within-subjects factors and participant gender was included as a between-subjects predictor. Age was re-centered again, as these analyses included only the adult-wave data. Attachment orientation (anxiety, avoidance) was predicted from age, age ${ }^{2}$, relationship status, and the interaction between these variables. Because relationship status was treated as a time-varying moderator of changes in attachment orientation, the effect of relationship status (and its interactions with age) can be interpreted as estimating the effect of being in a relationship at a particular wave and whether changes in status within individuals across the study were associated with mean-level changes in attachment orientation over time. Gender was included as a covariate.

Results from the growth curve analyses are presented in Tables 5 (for anxiety) and 6 (for anxiety). Relationship status was associated with lower anxiety and avoidance throughout adulthood. For both anxiety and avoidance, a significant age $^{2} \times$ relationship status interaction 
emerged as significant. Decomposing this interaction revealed that being single was associated with slightly sharper declines in older adulthood $(b=-.15, S E=.03, t(183.05)=-6.06, p<.001)$; the effect of $\mathrm{age}^{2}$ was not significant for individuals when partnered $(b=.02, S E=.02, t(620.35)$ $=.98, p=.33$ ). For avoidance, decomposing this interaction revealed that the age $\mathrm{e}^{2}$ estimate was non-significant for both being single $(b=-.03, p=.15)$ and partnered $(b=.02, p=.15)$. The model-implied trajectories for this pattern are presented in Figure 3.

\section{Discussion}

In the current study, we drew on data from five longitudinal studies of human development to examine mean-level changes in attachment orientation from age 13 to age 72. Anxiety was high throughout adolescence and young adulthood before declining throughout middle age and older adulthood. Avoidance showed smaller mean-level changes overall, but declined in a linear fashion across the lifespan. Being in a relationship was associated with greater attachment security over time. The current study is one of the first truly longitudinal investigations into lifespan changes in attachment orientation and the antecedents of these changes.

Worth noting, the magnitude of mean-level changes in attachment was relatively small. This observation, in combination with the moderate levels of stability we reported earlier, suggests that attachment may be relatively stable across the lifespan, although these average patterns may mask larger individual differences. Thus, attachment orientation could be conceptualized as a relatively stable disposition across the lifespan (Fraley, 2002; Zhang \& Labouvie-Vief, 2004). Nevertheless, the magnitude and direction of mean-level changes at each developmental period may provide additional insights into the role attachment plays in interpersonal behavior across the lifespan. In the following sections, we focus on how 
relationships at each stage may predict how and why attachment changes. We close with some considerations for examining attachment orientations across the lifespan using Q-Sort methods in archival data.

\section{Early Life}

During adolescence, people begin to explore their identities and become increasingly independent from their parents (Erikson, 1968). Adolescents and young adults seek out new relationships and environments that challenge their existing views of the world (Arnett, 2000).

These new relationships and environments are particularly important from an attachment perspective. One of the most important transitions that occurs in early life involves shifting attachment needs away from parents and toward peers and romantic partners (Fraley \& Davis, 1997). Adolescents start depending more on their peers to serve certain functions (Allen \& Tan, 2017; Heffernan et al., 2012): they enjoy spending more time with friends than with their parents (i.e., proximity-seeking functions), they increasingly want to be around friends when they feel sad or need advice (i.e., safe-haven functions), and they are more likely to feel that their friends are people they can count on (i.e., secure-base functions)(Rubin et al., 2004). This transition can be very stressful for adolescents as they navigate new relationships, forge new friendships, and test the strength of these bonds (Furman \& Shaffer, 2003; Furman et al., 2002a, 2002b). Starting romantic relationships for the first time can also be the cause of great anxiety as adolescents and young adults learn the social norms around dating and have their first dating experiences (Laner \& Ventrone, 2000). Because of these shifting roles and new experiences, adolescents may experience higher and more stable levels of anxiety, as they are unsure about the reliability and availability of new relationship partners (Brenning et al., 2013).

People in our study did not change as dramatically with respect to attachment avoidance 
during the early part of life, but generally decreased. People's avoidance could change more after they have gained additional relationship experience. Future research can examine the antecedents of changes in attachment throughout this period as well as the consequences for individual differences in rates of mean-level changes in attachment orientation (Arriaga et al., 2017).

\section{Middle Life}

From an attachment perspective, the increased social responsibility of midlife has the potential to change individuals' approaches toward social relationships. Starting long-term relationships, having children, and various occupational transitions place pressure on individuals to be more responsible, mature, and affectionate, particularly with respect to their loved ones (Boyce et al., 2015; Wood \& Roberts, 2006). For example, people generally become more emotional and sociable toward close others following the birth of a child (Jokela et al., 2009; Roberts \& Caspi, 2003).

Perhaps the largest piece of evidence supporting the premise that social responsibility increases attachment security is that individuals in relationships had lower levels of anxiety and avoidance across middle age. As Davila and colleagues (1997; 1999) note, increases in security often result from people becoming more comfortable in their relationships, gaining more evidence that the relationship will last, and having spouses who serve attachment needs and functions that promote close relations. Midlife is arguably the time during which individuals spend the most time and effort in gaining experience with respect to reciprocal interpersonal relationships. The influences of other, non-spousal relationships that occur in midlife on attachment orientation are less clear (Chopik, 2017). Are spousal relationships the greatest determinants of security in middle age? Or do other relationships contribute to security aboveand-beyond one's current romantic relationship (Hartup \& Stevens, 1999)? Future research can 
examine how relationships with spouses, friends, extended family, and children influence attachment orientations in midlife.

Examining how and why relationships change in midlife is particularly important given the growing body of literature showing the influence of these relationships on health. For instance, stressful relationships with friends, family, and children during midlife are associated with troubled sleep patterns, poor health and disability, greater allostatic load (i.e., a multisystem index of biological risk), inflammation, cortisol (i.e., a stress hormone), lower well-being, and even mortality (Ailshire \& Burgard, 2012; Bookwala, 2005; Brooks et al., 2014; Donoho, Crimmins, \& Seeman, 2013; Friedman et al., 2012; Greenfield \& Marks, 2006; Selcuk \& Ong, 2013). Given these associations, isolating the pathways through which attachment orientation, relationships, and changes in both attachment and relationships affect health and well-being is an important next step for future research (Bourassa, Sbarra, \& Whisman, 2015; LaBelle et al., 2015; Pietromonaco, Uchino, \& Dunkel Schetter, 2013).

\section{Late Life}

In older adulthood, anxiety and avoidance continued to decrease. Early research suggested that personality development might be most dramatic in early life and more stable in middle age and older adulthood (Roberts, Walton, \& Viechtbauer, 2006). However, recent evidence suggests that the many transitions that occur in older adulthood can also precipitate large changes, comparable to those found in young adults (Specht et al., 2014). The personality changes that occur later in life likely result from several processes, like new transitions (e.g., grandparenthood, retirement) or declines in health toward the end of life (Jokela et al., 2014; Lockenhoff, Terracciano, \& Costa, 2009; Somary \& Strieker, 1998; Wagner et al., 2015). With respect to attachment security, the process of aging has clear implications for how 
much and how well individuals invest in close relationships. As individuals age, there is an increasing sense that one's time becomes more limited (Carstensen et al., 1999). As such, individuals focus more on present-oriented goals that maximize well-being at the expense of future-oriented goals that maximize the acquisition of information and broadening one's horizons. One of the best ways to maximize well-being in old age is to invest in positive relationships with close loved ones rather than negative relationships or relationships with acquaintances (Fung, Carstensen, \& Lutz, 1999).

Because attachment insecurity can be a barrier to the formation and maintenance of close relationships (Davila \& Bradbury, 2001; Kirkpatrick \& Hazan, 1994; Schindler et al., 2010), declines in anxiety and avoidance may reflect the efforts of older adults to become closer to their close friends and family. Indeed, secure older adults are more selective with respect to their social networks, and this often translates to greater levels of familial support, more positive emotion, and lower levels of depression (Consedine \& Magai, 2003; Gillath et al., 2011; Merz \& Consedine, 2009).

Future research can examine how changes in attachment orientation throughout older adulthood can affect relationships and well-being within and between individuals. An individual's attachment orientation is related to how they respond to adverse experiences and how their loved ones interact with them in older adulthood (Van Assche et al., 2013). In older adulthood, one of the most obvious attachment-related life events that can occur is spousal bereavement (Shaver \& Fraley, 2008). The few studies examining how attachment predicts reactions to bereavement suggest that high levels of insecurity (i.e., high levels of anxiety and avoidance) and negative experiences with caregivers in childhood predict lower well-being (Fraley \& Bonanno, 2004; Sable, 1989). Despite this, the few studies conducted have been cross- 
sectional or rely on individuals' distant memories of their early attachment relationships, rather than their proximal attachment orientation prior to bereavement predicting adjustment across the bereavement experience. Thus, research on individual differences in attachment and reactions to life events in old age is relatively rare (Bradley \& Cafferty, 2001).

\section{The Measurement of Attachment Orientation in Archival Data}

We examined mean-level changes in attachment orientation across five different data sets to give a more comprehensive picture of how attachment orientation changes from age 13 to age 72. Nevertheless, limitations of the current study should be acknowledged. Many of the same limitations that befall accelerated longitudinal designs are also present in these data, but additional concerns about combining these data sets in particular are worth noting. The largest considerations that must be made is that this design combined data from (1) different sources, (2) from different researchers collected during (3) different time and historical periods from (4) different participants on which CAQ judgments were made on (5) different source material. Thus, there is no single individual for whom there are data available at both age 13 and age 72 . Rather, the data were combined to estimate age-related trends as if it were one contiguous sample. Sample source was added as a covariate in every analysis. Given the many ways in which these samples differed, the amount of consistency across the samples in estimating changes over time in attachment is even more remarkable. The converging evidence is a testament to the robustness of these results, such that they were found under different conditions in samples collected between 1936 and 2016.

The original researchers also did not necessarily intend to examine changes in attachment orientation across the lifespan. For example, many of the Intergenerational Studies were initiated to study the normal physical and intellectual development of children in the Berkeley/Oakland 
area. However, the flexibility in data collection and broad measures of personality that they included have enabled researchers to examine a wide array of topics, including the psychological effects of the Great Depression, women's work transitions, physical growth, and personality development (Elder, 1999; Elder, Downey, \& Cross, 1986). Although attachment orientation was not the explicit focus of any of these longitudinal studies, the fact that these results align well with studies in which attachment was the explicit focus also highlights the robustness of our results. Nevertheless, it should be noted that a more contemporary measure of attachment orientation would be a better standard of measurement, even though our CAQ measure of attachment correlates well with other, widely used measures of attachment. Further, studies in which attachment and relational behavior are the focus can assess additional variables that might predict changes and stability in attachment orientation over time (e.g., relationship quality). Modeling concurrent changes in relationship characteristics and attachment orientation across the lifespan is a useful direction for future research (Davila et al., 1999; Hirschberger et al., 2009).

Perhaps the greatest contribution of the current work is that a new measure was created to investigate longitudinal changes in attachment using data that had been collected over 80 years ago. The data collection window of these studies preceded not only the current conceptualization of individual differences in attachment but also the establishment of attachment theory (Bowlby, 1969/1982; Brennan et al., 1998; Chopik \& Edelstein, 2015). Relatedly, there is no single measure that adequately captures attachment orientation across the entire lifespan, making it particularly difficult to study changes over long developmental periods (Crowell et al., 2008; Magai, 2008). Fortunately, the prospective correlations between CAQ attachment measurements over long periods of time suggest that attachment-related dispositions can be assessed from adolescence until older adulthood (see Table 2 for a full list of test-retest correlations across the 
lifespan). Because there is some degree of stability in attachment over such long intervals, we can confidently say we are assessing the same underlying construct across the lifespan using this Q-Sort based measure of attachment. Nevertheless, researchers can explore other ways in which attachment can be reliably measured longitudinally from early life to late life.

\section{Conclusion}

The current report examined mean-level changes in attachment orientation from age 13 to age 72. Combining data from five different data sets allowed us to examine how attachment orientation changes over the longest interval to date, 59 years. Attachment anxiety was high throughout adolescence and young adulthood before declining across the lifespan. Attachment avoidance declined in a linear fashion across the lifespan. Being in a relationship was associated with greater attachment security. The current study provides a bird's eye view of how attachment changes across the lifespan. Future research can examine the influence of attachment orientation at each life stage and the enduring effects of early experiences, as well as address measurement issues inherent to assessing attachment orientation across the lifespan. By examining these future directions and identifying the conditions under which attachment orientations change, we can finally start taking seriously Bowlby's (1969/1982) claim that attachment experiences are important from the cradle to the grave. 


\section{References}

Ailshire, J. A., \& Burgard, S. A. (2012). Family relationships and troubled sleep among U.S. adults: examining the influences of contact frequency and relationship quality. Journal of Health and Social Behavior, 53(2), 248-262.

Allen, J. P., \& Tan, J. S. (2017). The multiple facets of attachment in adolescence. In J. Cassidy \& P. R. Shaver (Eds.), Handbook of attachment: Theory, research, and clinical applications (3rd ed., pp. 399-415). New York: The Guilford Press.

Arnett, J. J. (2000). Emerging adulthood: A theory of development from the late teens through the twenties. American Psychologist, 55(5), 469-480.

Arriaga, X. B., Kumashiro, M., Simpson, J. A., \& Overall, N. C. (2017). Revising working models across time: Relationship situations that enhance attachment security. Personality and Social Psychology Review, 1088868317705257.

Birnbaum, G. E. (2007). Attachment orientations, sexual functioning, and relationship satisfaction in a community sample of women. Journal of Social and Personal Relationships, 24(1), 21-35.

Block, J. (1961). The Q-sort method in personality assessment and psychiatric research. Springfield, Il: Charles C Thomas.

Block, J. (1971). Lives through time. Berkeley, CA: Bancroft Books.

Block, J. (2008). The Q-sort in character appraisal: Encoding subjective impressions of persons quantitatively. Washington, DC: American Psychological Association.

Block, J., \& Block, J. H. (1980). The California Child Q-Set. Palo Alto, CA: Consulting Psychologists Press.

Block, J., \& Block, J. H. (2006). Venturing a 30-year longitudinal study. American Psychologist, 
$61(4), 315-327$.

Bookwala, J. (2005). The role of marital quality in physical health during the mature years. Journal of Aging and Health, 17(1), 85-104.

Bourassa, K. J., Sbarra, D. A., \& Whisman, M. A. (2015). Women in very low quality marriages gain life satisfaction following divorce. Journal of Family Psychology, 29(3), 490-499.

Bowlby, J. (1969/1982). Attachement and loss: Vol. 1. Attachment. New York: Basic Books.

Bowlby, J. (1980). Attachment and loss, Vol. III, Loss: Sadness and depression. New York: Basic Books.

Boyce, C. J., Wood, A. M., Daly, M., \& Sedikides, C. (2015). Personality change following unemployment. Journal of Applied Psychology, 100(4), 991-1011.

Bradley, J. M., \& Cafferty, T. P. (2001). Attachment among older adults: Current issues and directions for future research. Attachment \& Human Development, 3(2), 200-221.

Brennan, K. A., Clark, C. L., \& Shaver, P. R. (1998). Self-report measurement of adult attachment: An integrative overview. In J. A. Simpson \& W. S. Rholes (Eds.), Attachment theory and close relationships. (pp. 46-76). New York, NY US: Guilford Press.

Brenning, K., Soenens, B., Braet, C., \& Beyers, W. (2013). Longitudinal dynamics of depressogenic personality and attachment dimensions in adolescence: An examination of associations with changes in depressive symptoms. Journal of Youth and Adolescence, 42(8), 1128-1144.

Brenning, K., Soenens, B., Braet, C., \& Bosmans, G. (2011). An adaptation of the Experiences in Close Relationships Scale-Revised for use with children and adolescents. Journal of Social and Personal Relationships, 28(8), 1048-1072. 
Brooks, K. P., Gruenewald, T., Karlamangla, A., Hu, P., Koretz, B., \& Seeman, T. E. (2014). Social relationships and allostatic load in the MIDUS study. Health Psychology, 33(11), 1373-1381.

Carstensen, L. L., Isaacowitz, D. M., \& Charles, S. T. (1999). Taking time seriously: A theory of socioemotional selectivity. American Psychologist, 54(3), 165-181.

Cassidy, J., \& Shaver, P. R. (2008). Handbook of attachment: Theory, research, and clinical applications (2nd ed.). New York, NY US: Guilford Press.

Chopik, W. J. (2017). Associations among relational values, support, health, and well-being across the adult lifespan. Personal Relationships.

Chopik, W. J., \& Edelstein, R. S. (2014). Age differences in romantic attachment around the world. Social Psychological and Personality Science, 5(8), 892-900.

Chopik, W. J., \& Edelstein, R. S. (2015). Preliminary validation of a romantic attachment orientation measure from the California Adult Q-Sort. Attachment and Human Development, 17(6), 570-585.

Chopik, W. J., Edelstein, R. S., \& Fraley, R. C. (2013). From the cradle to the grave: Age differences in attachment from early adulthood to old age. Journal of Personality, 81, 171-183.

Chopik, W. J., Edelstein, R. S., van Anders, S. M., Wardecker, B. M., Shipman, E. L., \& Samples-Steele, C. R. (2014). Too close for comfort? Adult attachment and cuddling in romantic and parent-child relationships. Personality and Individual Differences, 69, 212216.

Chopik, W. J., Moors, A. C., \& Edelstein, R. S. (2014). Maternal nurturance predicts decreases in attachment avoidance in emerging adulthood. Journal of Research in Personality, 
53(0), 47-53.

Consedine, N. S., \& Magai, C. (2003). Attachment and emotion experience in later life: the view from emotions theory. Attachment and Human Development, 5(2), 165-187.

Crowell, J. A., Fraley, R. C., \& Shaver, P. R. (2008). Measurement of individual differences in adolescent and adult attachment. In J. Cassidy \& P. R. Shaver (Eds.), Handbook of attachment: Theory, research, and clinical applications (2nd ed.). (pp. 599-634). New York, NY US: Guilford Press.

Davila, J., \& Bradbury, T. N. (2001). Attachment insecurity and the distinction between unhappy spouses who do and do not divorce. Journal of Family Psychology, 15(3), 371-393.

Davila, J., Burge, D., \& Hammen, C. (1997). Why does attachment style change? Journal of Personality and Social Psychology, 73(4), 826-838.

Davila, J., Karney, B. R., \& Bradbury, T. N. (1999). Attachment change processes in the early years of marriage. Journal of Personality and Social Psychology, 76(5), 783-802.

Diehl, M., Elnick, A. B., Bourbeau, L. S., \& Labouvie-Vief, G. (1998). Adult attachment styles: Their relations to family context and personality. Journal of Personality and Social Psychology, 74(6), 1656-1669.

Donoho, C. J., Crimmins, E. M., \& Seeman, T. E. (2013). Marital quality, gender, and markers of inflammation in the MIDUS cohort. Journal of Marriage and Family, 75(1), 127-141.

Edelstein, R. S., \& Gillath, O. (2008). Avoiding interference: Adult attachment and emotional processing biases. Personality and Social Psychology Bulletin, 34(2), 171-181.

Edelstein, R. S., \& Shaver, P. R. (2004). Avoidant attachment: Exploration of an oxymoron. In D. J. Mashek \& A. P. Aron (Eds.), Handbook of closeness and intimacy. (pp. 397-412). Mahwah, NJ US: Lawrence Erlbaum Associates Publishers. 
Eichorn, D. H., Clausen, J. A., Haan, N., Honzik, M. P., \& Mussen, P. H. (1981). Present and Past in Middle Life. New York: Academic Press.

Elder, G. H., Jr. (1999). Children of the Great Depression: Social change in life experience (25th anniversary ed.). Boulder, CO, US: Westview Press.

Elder, G. H., Jr., Downey, G., \& Cross, C. E. (1986). Family ties and life chances: Hard times and hard choices in women's lives since the 1930s. In N. Datan, A. L. Greene, \& H. W. Reese (Eds.), Life-span developmental psychology: Intergenerational relations. (pp. 151183). Hillsdale, NJ, England: Lawrence Erlbaum Associates, Inc.

Erikson, E. H. (1968). Identity: Youth and crisis. Oxford England: Norton \& Co.

Feddern Donbaek, D., \& Elklit, A. (2014). A validation of the Experiences in Close Relationships-Relationship Structures scale (ECR-RS) in adolescents. Attachment and Human Development, 16(1), 58-76.

Fraley, R. C. (2002). Attachment stability from infancy to adulthood: Meta-analysis and dynamic modeling of developmental mechanisms. Personality and Social Psychology Review, $6(2), 123-151$.

Fraley, R. C. (2007). A connectionist approach to the organization and continuity of working models of attachment. Journal of Personality, 75(6), 1157-1180.

Fraley, R. C., \& Bonanno, G. A. (2004). Attachment and loss: A test of three competing models on the association between attachment-related avoidance and adaptation to bereavement. Personality and Social Psychology Bulletin, 30(7), 878-890.

Fraley, R. C., \& Davis, K. E. (1997). Attachment formation and transfer in young adults' close friendships and romantic relationships. Personal Relationships, 4(2), 131-144.

Fraley, R. C., Davis, K. E., \& Shaver, P. R. (1998). Dismissing-avoidance and the defensive 
organization of emotion, cognition, and behavior. In J. A. Simpson \& W. S. Rholes (Eds.), Attachment theory and close relationships. (pp. 249-279). New York, NY US: Guilford Press.

Fraley, R. C., Niedenthal, P. M., Marks, M., Brumbaugh, C., \& Vicary, A. (2006). Adult attachment and the perception of emotional expressions: Probing the hyperactivating strategies underlying anxious attachment. Journal of Personality, 74(4), 1163-1190.

Fraley, R. C., \& Roberts, B. W. (2005). Patterns of continuity: A dynamic model for conceptualizing the stability of individual differences in psychological constructs across the life course. Psychological Review, 112(1), 60-74.

Fraley, R. C., \& Roisman, G. I. (2015). Do early caregiving experiences leave an enduring or transient mark on developmental adaptation? Current Opinion in Psychology, 1, 101-106.

Fraley, R. C., Roisman, G. I., \& Haltigan, J. D. (2013). The legacy of early experiences in development: Formalizing alternative models of how early experiences are carried forward over time. Developmental Psychology, 49(1), 109-126.

Fraley, R. C., Vicary, A. M., Brumbaugh, C. C., \& Roisman, G. I. (2011). Patterns of stability in adult attachment: An empirical test of two models of continuity and change. Journal of Personality and Social Psychology, 101(5), 974-992.

Fraley, R. C., \& Waller, N. G. (1998). Adult attachment patterns: A test of the typological model. In J. A. Simpson \& W. S. Rholes (Eds.), Attachment theory and close relationships. (pp. 77-114). New York, NY US: Guilford Press.

Friedman, E. M., Karlamangla, A. S., Almeida, D. M., \& Seeman, T. E. (2012). Social strain and cortisol regulation in midlife in the US. Social Science and Medicine, 74(4), 607-615.

Fung, H. H., Carstensen, L. L., \& Lutz, A. M. (1999). Influence of time on social preferences: 
implications for life-span development. Psychology and Aging, 14(4), 595-604.

Furman, W., \& Shaffer, L. (2003). The role of romantic relationships in adolescent development. In P. Florsheim (Ed.), Adolescent romantic relations and sexual behavior: Theory, research, and practical implications (pp. 3-22). Mahwah, NJ: Lawrence Erlbaum Associates.

Furman, W., Simon, V., Shaffer, L., \& Bouchey, H. A. (2002a). Adolescent romantic relations and sexual behavior: Theory, research, and practical implications. Journal of Youth and Adolescence, 28, 516-522.

Furman, W., Simon, V., Shaffer, L., \& Bouchey, H. A. (2002b). Adolescents' working models and styles for relationships with parents, friends, and romantic partners. Child Development, 73(1), 241-255.

Gillath, O., Johnson, D. K., Selcuk, E., \& Teel, C. (2011). Comparing old and young adults as they cope with life transitions: The links between social network management skills and attachment style to depression. Clinical Gerontologist, 34(3), 251-265.

Greenfield, E. A., \& Marks, N. F. (2006). Linked lives: adult children's problems and their parents' psychological and relational well-Being. Journal of Marriage and Family, 68(2), 442-454.

Gross, J. J., Carstensen, L. L., Pasupathi, M., Tsai, J., Skorpen, C. G., \& Hsu, A. Y. C. (1997). Emotion and aging: Experience, expression, and control. Psychology and Aging, 12(4), $590-599$.

Haan, N., Millsap, R., \& Hartka, E. (1986). As time goes by: Change and stability in personality over fifty years. Psychology and Aging, 1(3), 220-232.

Hartup, W. W., \& Stevens, N. (1999). Friendships and adaptation across the life span. Current 
Directions in Psychological Science, 8(3), 76-79.

Heffernan, M. E., Fraley, R. C., Vicary, A. M., \& Brumbaugh, C. C. (2012). Attachment features and functions in adult romantic relationships. Journal of Social and Personal Relationships, 29(5), 671-693.

Helson, R., Jones, C., \& Kwan, V. S. Y. (2002). Personality change over 40 years of adulthood: Hierarchical linear modeling analyses of two longitudinal samples. Journal of Personality and Social Psychology, 83(3), 752-766.

Hirschberger, G., Srivastava, S., Marsh, P., Cowan, C. P., \& Cowan, P. A. (2009). Attachment, marital satisfaction, and divorce during the first fifteen years of parenthood. Personal Relationships, 16(3), 401-420.

Hudson, N. W., Fraley, R. C., Chopik, W. J., \& Heffernan, M. E. (2015). Not all attachment relationships develop alike: Normative cross-sectional age trajectories in attachment to romantic partners, best friends, and parents. Journal of Research in Personality, 59, 4455.

Jokela, M., Hakulinen, C., Singh-Manoux, A., \& Kivimaki, M. (2014). Personality change associated with chronic diseases: pooled analysis of four prospective cohort studies. Psychological Medicine, 44(12), 2629-2640.

Jokela, M., Kivimaki, M., Elovainio, M., \& Keltikangas-Jarvinen, L. (2009). Personality and having children: a two-way relationship. Journal of Personality and Social Psychology, 96(1), 218-230.

Kirkpatrick, L. A., \& Hazan, C. (1994). Attachment styles and close relationships: A four-year prospective study. Personal Relationships, 1(2), 123-142.

Klohnen, E. C., \& John, O. P. (1998). Working models of attachment: A theory-based prototype 
approach. In J. A. Simpson \& W. S. Rholes (Eds.), Attachment theory and close relationships. (pp. 115-140). New York, NY US: Guilford Press.

Konrath, S. H., Chopik, W. J., Hsing, C., \& O'Brien, E. (2013). Dismissing attachment styles are increasing in American college students over time: A meta-analysis. Manuscript submitted for publication.

LaBelle, O., P., Wardecker, B. M., Chopik, W. J., \& Edelstein, R. S. (2015). Attachment Processes. In K. Sweeny \& M. Robbins (Eds.), Wiley Encyclopedia of Health Psychology.

Laner, M. R., \& Ventrone, N. A. (2000). Dating scripts revisited. Journal of Family Issues, 21(4), 488-500.

Li, T., \& Chan, D. K. S. (2012). How anxious and avoidant attachment affect romantic relationship quality differently: A meta-analytic review. European Journal of Social Psychology, 42(4), 406-419.

Lockenhoff, C. E., Terracciano, A., \& Costa, P. T. (2009). Five-factor model personality traits and the retirement transition: longitudinal and cross-sectional associations. Psychology and Aging, 24(3), 722-728.

Magai, C. (2008). Attachment in middle and later life. In J. Cassidy \& P. R. Shaver (Eds.), Handbook of attachment: Theory, research, and clinical applications (2nd ed.). (pp. 532551). New York, NY US: Guilford Press.

Magai, C., Cohen, C., Milburn, N., Thorpe, B., McPherson, R., \& Peralta, D. (2001). Attachment styles in older European American and African American adults. The Journals of Gerontology: Series B: Psychological Sciences and Social Sciences, 56B(1), S28-S35.

Merz, E. M., \& Consedine, N. S. (2009). The association of family support and wellbeing in later 
life depends on adult attachment style. Attachment and Human Development, 11(2), 203221.

Mickelson, K. D., Kessler, R. C., \& Shaver, P. R. (1997). Adult attachment in a nationally representative sample. Journal of Personality and Social Psychology, 73(5), 1092-1106.

Mikulincer, M., Gillath, O., \& Shaver, P. R. (2002). Activation of the attachment system in adulthood: Threat-related primes increase the accessibility of mental representations of attachment figures. Journal of Personality and Social Psychology, 83(4), 881-895.

Miyazaki, Y., \& Raudenbush, S. W. (2000). Tests for linkage of multiple cohorts in an accelerated longitudinal design. Psychological Methods, 5(1), 44-63.

Noftle, E. E., \& Shaver, P. R. (2006). Attachment dimensions and the big five personality traits: Associations and comparative ability to predict relationship quality. Journal of Research in Personality, 40(2), 179-208.

Peugh, J. L., \& Enders, C. K. (2005). Using the SPSS Mixed Procedure to Fit Cross-Sectional and Longitudinal Multilevel Models. Educational and Psychological Measurement, $65(5), 717-741$

Pietromonaco, P. R., Uchino, B., \& Dunkel Schetter, C. (2013). Close relationship processes and health: Implications of attachment theory for health and disease. Health Psychology, 32(5), 499-513.

Raudenbush, S. W., \& Chan, W.-s. (1992). Growth curve analysis in accelerated longitudinal designs. Journal of Research in Crime and Delinquency, 29(4), 387-411.

Roberts, B. W., \& Caspi, A. (2003). The cumulative continuity model of personality development: Striking a balance between continuity and change in personality traits across the life course. In U. Staudinger \& U. Lindenberger (Eds.), Understanding Human 
Development (pp. 183-214): Springer US.

Roberts, B. W., \& Chapman, C. N. (2000). Change in dispositional well-being and its relation to role quality: A 30-year longitudinal study. Journal of Research in Personality, 34(1), 2641.

Roberts, B. W., Walton, K. E., \& Viechtbauer, W. (2006). Patterns of mean-level change in personality traits across the life course: A meta-analysis of longitudinal studies. Psychological Bulletin, 132(1), 1-25.

Roberts, B. W., Wood, D., \& Smith, J. L. (2005). Evaluating Five Factor Theory and social investment perspectives on personality trait development. Journal of Research in Personality, 39(1), 166-184.

Rubin, K. H., Dwyer, K. M., Kim, A. H., Burgess, K. B., Booth-LaForce, C., \& Rose-Krasnor, L. (2004). Attachment, Friendship, and Psychosocial Functioning in Early Adolescence. The Journal of early adolescence, 24(4), 326-356.

Sable, P. (1989). Attachment, anxiety, and loss of a husband. American Journal of Orthopsychiatry, 59(4), 550-556.

Satterthwaite, F. E. (1946). An approximate distribution of estimates of variance components. Biometrics Bulletin, 2(6), 110-114.

Schimmack, U. (2012). The ironic effect of significant results on the credibility of multiple-study articles. Psychological Methods, 17(4), 551-566.

Schindler, I., Fagundes, C. P., \& Murdock, K. W. (2010). Predictors of romantic relationship formation: Attachment style, prior relationships, and dating goals. Personal Relationships, 17(1), 97-105.

Selcuk, E., \& Ong, A. D. (2013). Perceived partner responsiveness moderates the association 
between received emotional support and all-cause mortality. Health Psychology, 32(2), 231-235.

Shaver, P. R., \& Fraley, R. C. (2008). Attachment, loss, and grief: Bowlby's views and current controversies. In J. Cassidy \& P. R. Shaver (Eds.), Handbook of attachment: Theory, research, and clinical applications (2nd ed.). (pp. 48-77). New York, NY US: Guilford Press.

Shaver, P. R., Schachner, D. A., \& Mikulincer, M. (2005). Attachment style, excessive reassurance seeking, relationship processes, and depression. Personality and Social Psychology Bulletin, 31(3), 343-359.

Somary, K., \& Strieker, G. (1998). Becoming a grandparent: A longitudinal study of expectations and early experiences as a function of sex and lineage. The Gerontologist, 38(1), 53-61.

Specht, J., Bleidorn, W., Denissen, J. J. A., Hennecke, M., Hutteman, R., Kandler, C., . . . Zimmermann, J. (2014). What drives adult personality development? A comparison of theoretical perspectives and empirical evidence. European Journal of Personality, 28(3), 216-230.

Stewart, A. J., \& Vandewater, E. A. (1993). The Radcliffe class of 1964: Career and family social clock projects in a transitional cohort. In K. D. Hulbert \& D. T. Schuster (Eds.), Women's lives through time: Educated American women of the twentieth century. (pp. 235-258). San Francisco, CA US: Jossey-Bass.

Terracciano, A., McCrae, R. R., Brant, L. J., \& Costa, P. T. (2005). Hierarchical linear modeling analyses of NEO-PI-R scales in the Baltimore Longitudinal Study of Aging. Psychology and Aging, 20(3), 493-506. 
Van Assche, L., Luyten, P., Bruffaerts, R., Persoons, P., van de Ven, L., \& Vandenbulcke, M. (2013). Attachment in old age: Theoretical assumptions, empirical findings and implications for clinical practice. Clinical Psychology Review, 33(1), 67-81.

Wagner, J., Ram, N., Smith, J., \& Gerstorf, D. (2015). Personality trait development at the end of life: Antecedents and correlates of mean-level trajectories. Journal of Personality and Social Psychology.

Wardecker, B. M., Chopik, W. J., Moors, A. C., \& Edelstein, R. S. (2017). Avoidant attachment style. In V. Ziegler-Hill \& T. K. Shackelford (Eds.), Encyclopedia of Personality and Individual Differences.

Whitbourne, S. K., \& Tesch, S. A. (1985). A comparison of identity and intimacy statuses in college students and alumni. Developmental Psychology, 21, 1039-1044.

Wilkinson, R. B. (2011). Measuring Attachment Dimensions in Adolescents: Development and Validation of the Experiences in Close Relationships — Revised — General Short Form. Journal of Relationships Research, 2(1), 53-62.

Willett, J. B. (1988). Questions and answers in the measurement of change. Review of Research in Education, 15, 345-422.

Wood, D., \& Roberts, B. W. (2006). The effect of age and role information on expectations for big five personality traits. Personality and Social Psychology Bulletin, 32(11), 14821496.

Zhang, F., \& Labouvie-Vief, G. (2004). Stability and fluctuation in adult attachment style over a 6-year period. Attachment \& Human Development, 6(4), 419-437. 
Table 1. Summary of Study Designs and Sample Sizes

\begin{tabular}{ccccccr}
\hline & Block & Guidance & Growth & Oakland & Radcliffe & \\
\hline $\begin{array}{c}\text { Approximate } \\
\text { Birth Year: }\end{array}$ & 1969 & 1929 & 1929 & 1923 & 1943 & $\begin{array}{r}\text { Total } \\
\text { Observations } \\
\text { at Each Wave }\end{array}$ \\
\hline Age & & & & & & n \\
\hline 13 & & 73 & 39 & 97 & & 109 \\
14 & 106 & & & & & 200 \\
16 & & 66 & 40 & 94 & & 104 \\
18 & 104 & & & & & 103 \\
23 & 103 & & & & & 133 \\
30 & & 133 & & & & 50 \\
36 & & & 50 & & & 235 \\
40 & & 136 & & 99 & & 103 \\
43 & & & & & & 97 \\
50 & & & & 97 & & 192 \\
52 & & 142 & 50 & & 109 & 109 \\
53 & & & & & & 91 \\
60 & & & & 91 & 99 & 109 \\
62 & & & & & 109 & \\
73 & & & & & & 167 \\
\hline Total $n:$ & 107 & 171 & 62 & 121 & 167 \\
\hline
\end{tabular}

Note. Ns based on number of individuals with at least one assessment of attachment and thus do not sum to the total $\mathrm{N}$ for each sample. 
Table 2. Test-retest Correlations of Attachment Orientation at Every Time Point

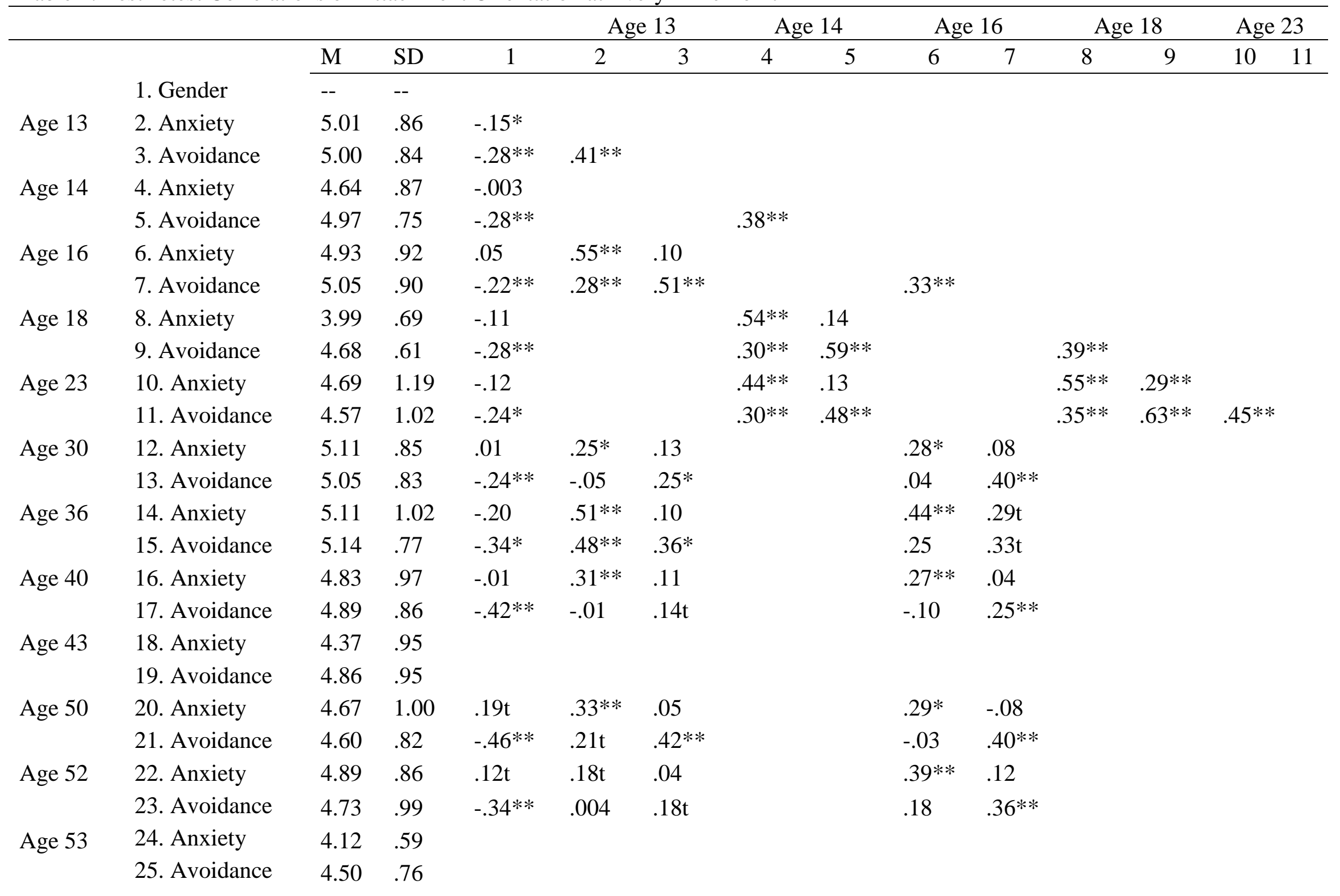




\begin{tabular}{lllllllll} 
Age 60 & 26. Anxiety & 4.66 & .92 & .14 & $.23 \mathrm{t}$ & .17 & .06 & .003 \\
& 27. Avoidance & 4.70 & .76 & $-.28 * *$ & -.03 & $.38 * *$ & -.06 & $.33 * *$ \\
Age 62 & 28. Anxiety & 4.11 & .63 & & & & \\
& 29. Avoidance & 4.40 & .58 & & & & \\
Age 72 & 30. Anxiety & 3.98 & .59 & & & & \\
& 31. Avoidance & 4.27 & .66 & & & & \\
\hline
\end{tabular}


Table 2 (con't)

\begin{tabular}{|c|c|c|c|c|c|c|c|c|c|c|c|c|c|c|c|c|c|c|c|}
\hline & & \multicolumn{2}{|c|}{ Age 30} & \multicolumn{2}{|c|}{ Age 36} & \multicolumn{2}{|c|}{ Age 40} & \multicolumn{2}{|c|}{ Age 43} & \multicolumn{2}{|c|}{ Age 50} & Age 52 & \multicolumn{2}{|c|}{ Age 53} & \multicolumn{2}{|c|}{ Age 60} & \multicolumn{2}{|c|}{ Age 62} & \multirow{2}{*}{$\begin{array}{c}\text { Age } \\
72 \\
30\end{array}$} \\
\hline & & 12 & 13 & 14 & 15 & 16 & 17 & 18 & 19 & 20 & 21 & $22 \quad 23$ & 24 & 25 & 26 & 27 & 28 & 29 & \\
\hline \multirow[t]{2}{*}{ Age 30} & 12. Anxiety & & & & & & & & & & & & & & & & & & \\
\hline & 13. Avoidance & $.35 * *$ & & & & & & & & & & & & & & & & & \\
\hline \multirow[t]{2}{*}{ Age 36} & 14. Anxiety & & & & & & & & & & & & & & & & & & \\
\hline & 15. Avoidance & & & $.55^{* *}$ & & & & & & & & & & & & & & & \\
\hline \multirow[t]{2}{*}{ Age 40} & 16. Anxiety & $.25 * *$ & -.01 & & & & & & & & & & & & & & & & \\
\hline & 17. Avoidance & -.01 & $.36 * *$ & & & $.14^{*}$ & & & & & & & & & & & & & \\
\hline \multirow[t]{2}{*}{ Age 43} & 18. Anxiety & & & & & & & & & & & & & & & & & & \\
\hline & 19. Avoidance & & & & & & & & & & & & & & & & & & \\
\hline \multirow[t]{2}{*}{ Age 50} & 20. Anxiety & & & & & $.69 * *$ & -.04 & & & & & & & & & & & & \\
\hline & 21. Avoidance & & & & & -.06 & $.57 * *$ & & & & & & & & & & & & \\
\hline \multirow[t]{2}{*}{ Age 52} & 22. Anxiety & $.36 * *$ & -.02 & .26 & -.02 & $.40 * *$ & -.05 & & & & & & & & & & & & \\
\hline & 23. Avoidance & .13 & $.30 * *$ & .22 & $.37 *$ & .05 & $.46 * *$ & & & & & $.30 * *$ & & & & & & & \\
\hline \multirow[t]{2}{*}{ Age 53} & 24. Anxiety & & & & & & & $.59 * *$ & $.32 * *$ & & & & & & & & & & \\
\hline & 25. Avoidance & & & & & & & $.29 *$ & $.74 * *$ & & & & $.23 *$ & & & & & & \\
\hline \multirow[t]{2}{*}{ Age 60} & 26. Anxiety & & & & & $.56 * *$ & -.07 & & & $.50 * *$ & -.02 & & & & & & & & \\
\hline & 27. Avoidance & & & & & .06 & $.41 * *$ & & & .14 & $.51 * *$ & & & & $.28 * *$ & & & & \\
\hline \multirow[t]{2}{*}{ Age 62} & 28. Anxiety & & & & & & & $.49 * *$ & .07 & & & & $.53 * *$ & .14 & & & & & \\
\hline & 29. Avoidance & & & & & & & $.22 \mathrm{t}$ & $.60 * *$ & & & & $.29 *$ & $.71 * *$ & & & $.29 * *$ & & \\
\hline \multirow[t]{2}{*}{ Age 72} & 30. Anxiety & & & & & & & $.54 * *$ & 0.1 & & & & $.40 * *$ & $.30 * *$ & & & $.50 * * *$ & $.20 \mathrm{t}$ & \\
\hline & 31. Avoidance & & & & & & & $.23 \mathrm{t}$ & $.55 * *$ & & & & $.19 \mathrm{t}$ & $.62 * *$ & & & .17 & $.62 * *$ & $.21 *$ \\
\hline
\end{tabular}


Table 3. Growth Curve Modeling Predicting Attachment Anxiety from Age and Gender

\begin{tabular}{|c|c|c|c|c|c|c|}
\hline & \multicolumn{6}{|c|}{ Anxiety } \\
\hline & $b$ & $S E(b)$ & $d f$ & $b_{z}$ & $t$ & $p$ \\
\hline Intercept & 4.37 & .08 & & & & \\
\hline Age & -.11 & .02 & 1659.56 & -.11 & -5.70 & $<.001$ \\
\hline Gender & -.01 & .04 & 1182.82 & -.01 & -.33 & .74 \\
\hline Age $\times$ Gender & .06 & .02 & 1629.00 & .06 & 3.36 & .001 \\
\hline $\mathrm{Age}^{2}$ & -.04 & .01 & 1900.02 & -.04 & -4.00 & $<.001$ \\
\hline $\mathrm{Age}^{2} \times$ Gender & .02 & .01 & 1913.09 & .02 & 1.91 & .06 \\
\hline Oakland & .65 & .09 & 931.73 & & 7.10 & $<.001$ \\
\hline Guidance & .53 & .09 & 991.50 & & 5.92 & $<.001$ \\
\hline Growth & .59 & .11 & 943.64 & & 5.36 & $<.001$ \\
\hline Block \& Block & .12 & .11 & 1019.35 & & 1.08 & .28 \\
\hline
\end{tabular}

Note. Gender: $-1=$ men, $1=$ women. The Radcliffe College Sample served as the reference group against which the other samples were compared. Age is scaled by decade of life (i.e., 10 years). The effect size $b_{z}$ represents the beta coefficient when anxiety is standardized and the model is re-run; the coefficients were very similar when standardized for analyses involving attachment anxiety. 
Table 4. Growth Curve Modeling Predicting Attachment Avoidance from Age and Gender

\begin{tabular}{lllllll}
\hline & \multicolumn{7}{c}{ Avoidance } \\
\cline { 2 - 7 } & $b$ & $S E(b)$ & $d f$ & $b_{z}$ & $t$ & $p$ \\
\hline Intercept & 5.06 & .07 & & & & \\
Age & -.09 & .02 & 1694.37 & -.10 & -5.27 & $<.001$ \\
Gender & -.28 & .04 & 1145.79 & -.33 & -7.83 & $<.001$ \\
Age $\times$ Gender & -.02 & .02 & 1659.06 & -.03 & -1.46 & .15 \\
Age $^{2}$ & -.01 & .01 & 1856.84 & -.02 & -1.59 & .11 \\
Age $^{2} \times$ Gender & .004 & .01 & 1877.10 & .01 & .51 & .61 \\
Oakland $_{\text {Guidance }}$ & -.15 & .08 & 878.59 & & -1.86 & .06 \\
Growth & -.06 & .08 & 941.75 & & -.74 & .46 \\
Block \& Block & -.09 & .10 & 876.47 & & -.92 & .36 \\
\hline Note. Gencr & -.40 & .10 & 1003.44 & & -3.91 & $<.001$ \\
\hline
\end{tabular}

Note. Gender: -1 = men, 1 = women. The Radcliffe College Sample served as the reference group against which the other samples were compared. Age is scaled by decade of life (i.e., 10 years). The effect size $b_{z}$ represents the beta coefficient when avoidance is standardized and the model is re-run. 
Table 5. Growth Curve Modeling Predicting Attachment Anxiety from Age, Gender, and Relationship Status

\begin{tabular}{|c|c|c|c|c|c|c|}
\hline & \multicolumn{6}{|c|}{ Anxiety } \\
\hline & $b$ & $S E(b)$ & $d f$ & $b_{z}$ & $t$ & $p$ \\
\hline Intercept & 4.38 & .08 & & & & \\
\hline Age & -.07 & .03 & 1225.06 & -.07 & -.2 .06 & .04 \\
\hline Gender & .02 & .04 & 550.18 & .02 & .42 & .67 \\
\hline Relationship Status & -.24 & .05 & 844.90 & -.25 & -4.98 & $<.001$ \\
\hline Age $\times$ R. Status & -.03 & .02 & 1024.88 & -.03 & -1.59 & .11 \\
\hline $\mathrm{Age}^{2}$ & -.05 & .01 & 833.87 & -.05 & -3.62 & $<.001$ \\
\hline $\operatorname{Age}^{2} \times$ R. Status & .03 & .01 & 1248.94 & .03 & 3.19 & .001 \\
\hline Oakland & .72 & .11 & 525.22 & & 6.65 & $<.001$ \\
\hline Guidance & .64 & .10 & 635.33 & & 6.35 & $<.001$ \\
\hline Growth & .75 & .13 & 657.00 & & 5.75 & $<.001$ \\
\hline Block \& Block & .06 & .18 & 1282.69 & & .35 & .72 \\
\hline
\end{tabular}

Note . Gender: $-1=$ men, $1=$ women. Status: $-1=$ single, $1=$ partnered. The Radcliffe College Sample served as the reference group against which the other samples were compared. Age is scaled by decade of life (i.e., 10 years). The effect size $b_{z}$ represents the beta coefficient when anxiety is standardized and the model is re-run. 
Table 6. Growth Curve Modeling Predicting Attachment Avoidance from Age, Gender, and Relationship Status

\begin{tabular}{lllllll}
\hline & \multicolumn{7}{c}{ Avoidance } \\
\cline { 2 - 7 } & $b$ & $S E(b)$ & $d f$ & $b_{z}$ & $t$ & $p$ \\
\hline Intercept & 5.01 & .07 & & & & \\
Age & -.16 & .03 & 1210.75 & -.19 & -5.95 & $<.001$ \\
Gender & -.27 & .03 & 548.34 & -.32 & -8.52 & $<.001$ \\
Relationship Status & -.21 & .04 & 835.03 & -.24 & -4.95 & $<.001$ \\
Age $\times$ R. Status & .01 & .02 & 1055.18 & .01 & .72 & .47 \\
Age & -.0004 & .01 & 827.73 & -.0004 & -.03 & .97 \\
Age & .02 & .01 & 1231.73 & .02 & 1.99 & .05 \\
Oakland & .04 & .09 & 521.99 & & .48 & .63 \\
Guidance & .02 & .09 & 623.32 & & .29 & .77 \\
Growth & .15 & .11 & 630.27 & & 1.35 & .18 \\
Block \& Block & -.76 & .15 & 1278.64 & & -5.02 & $<.001$ \\
\hline
\end{tabular}

Note . Gender: $-1=$ men, $1=$ women. Status: $-1=$ single, $1=$ partnered. The Radcliffe College Sample served as the reference group against which the other samples were compared. Age is scaled by decade of life (i.e., 10 years). The effect size $b_{z}$ represents the beta coefficient when avoidance is standardized and the model is re-run. 


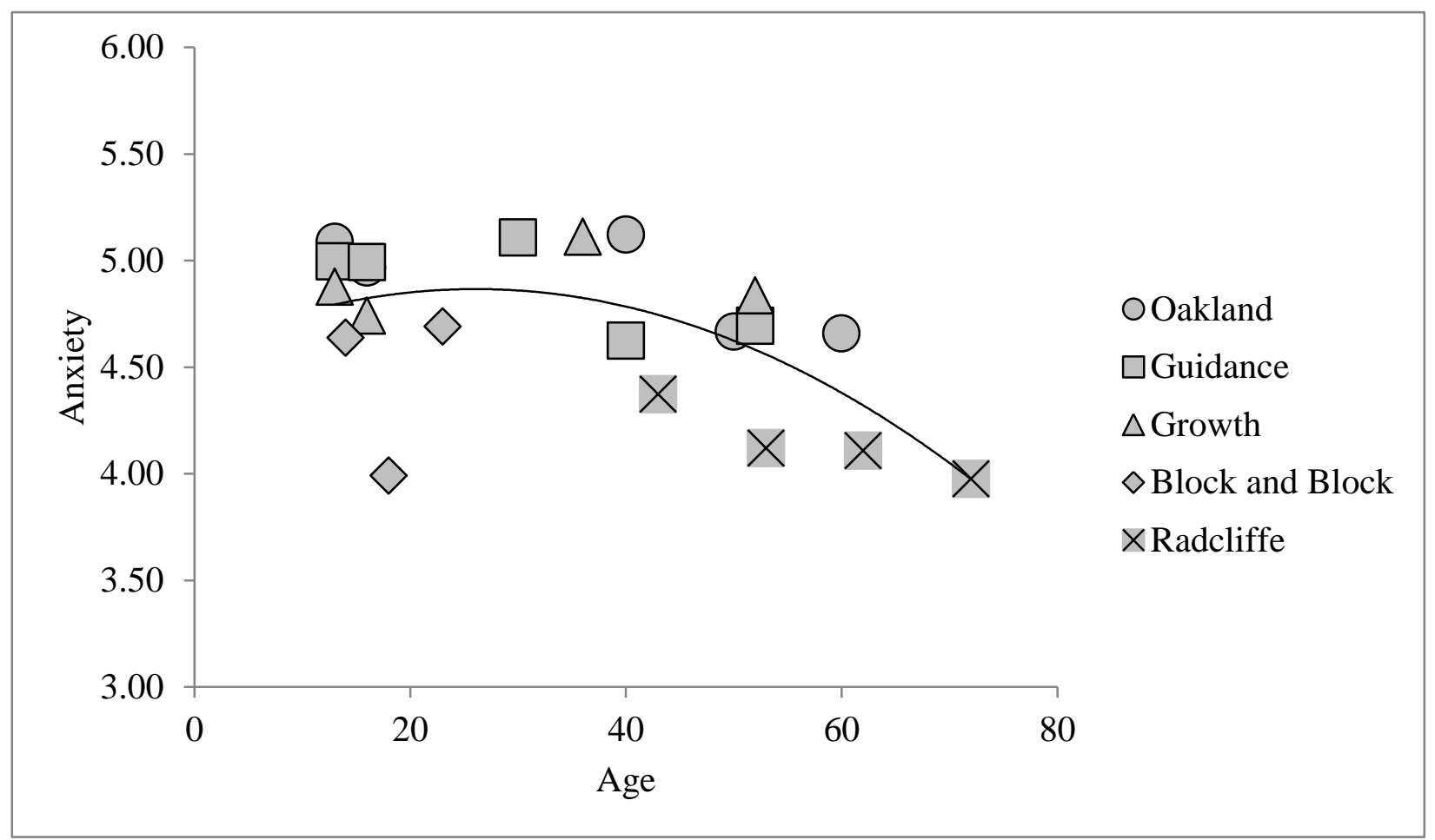

Figure 1. Longitudinal mean-level changes in anxiety. The model implied quadratic function is plotted with unconditional means from each individual sample superimposed into the figure. 


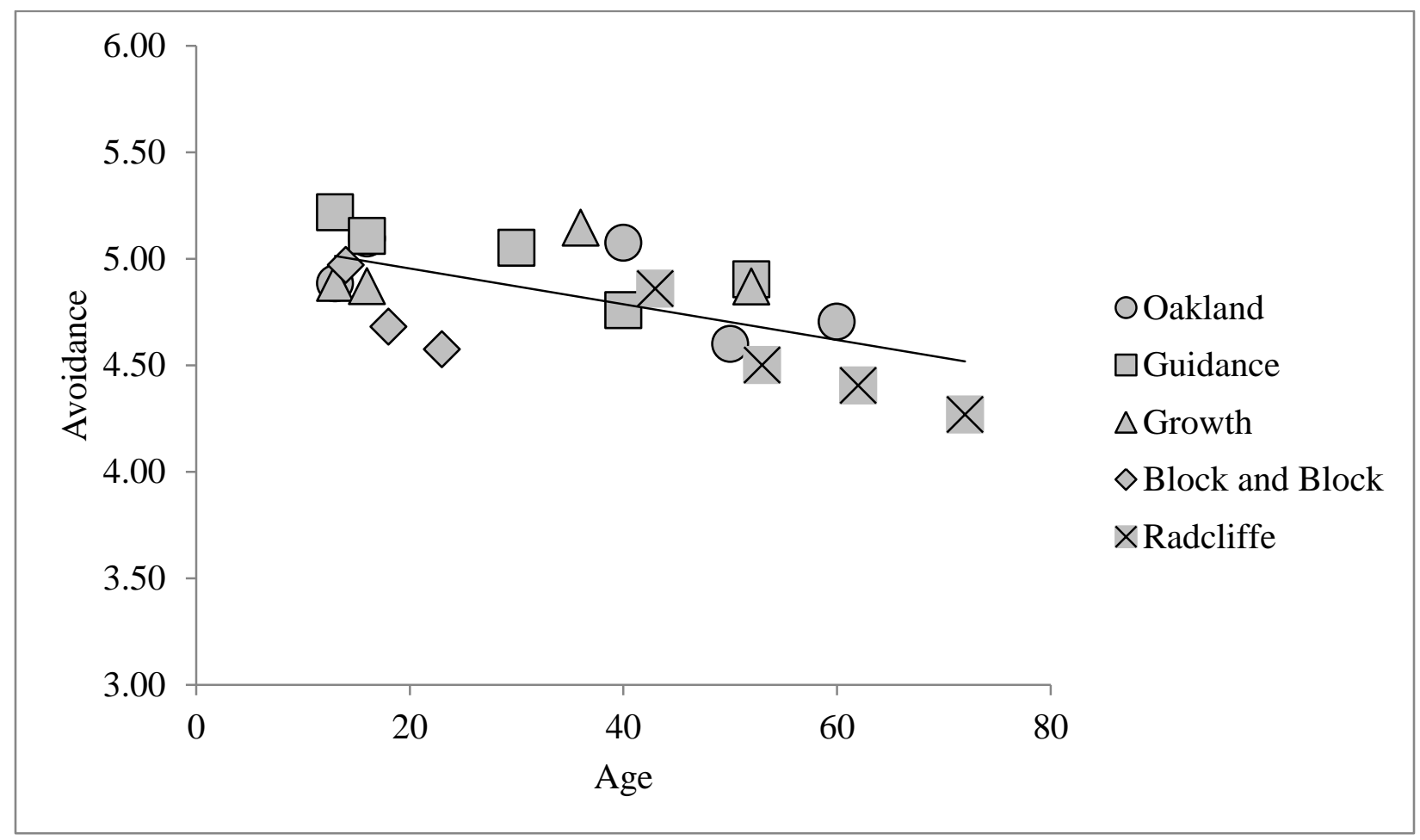

Figure 2. Longitudinal mean-level changes in avoidance. The model implied linear function is plotted with unconditional means from each individual sample superimposed into the figure. 


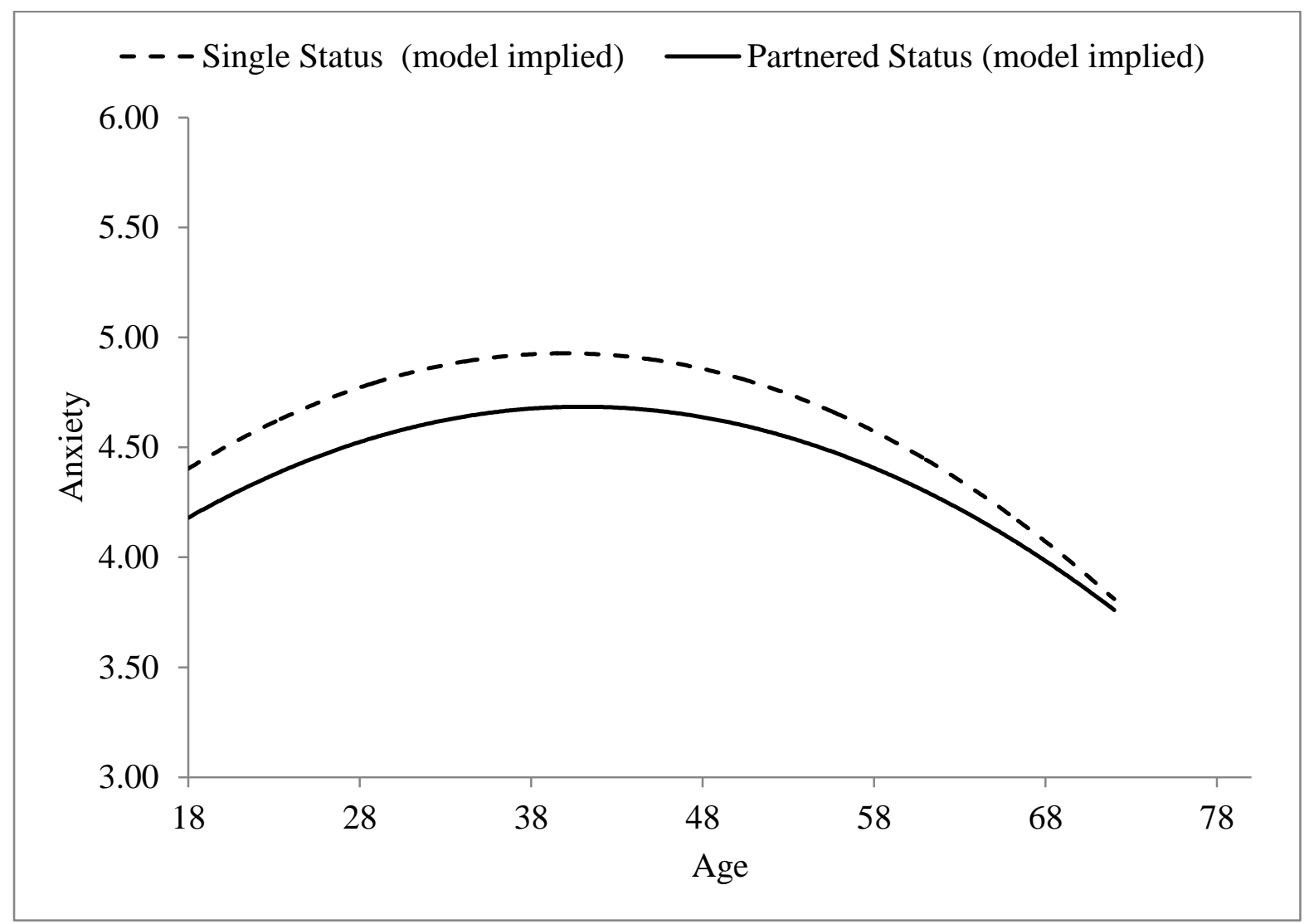

Figure 3. Longitudinal mean-level changes in anxiety plotted separately for single and partnered status at each wave. The model implied quadratic function is plotted. 


\section{Endnotes}

${ }^{1}$ The data sets described here also include a number of childhood waves, some of which include Q-Sort data (see Block, 1971; Block \& Block, 1980; Block \& Block, 2006). However, the extent to which attachment exhibits heterotypical continuity and, as a result, can be measured with the same instrument across the entire lifespan is currently controversial (Allen \& Tan, 2017;

Crowell, Fraley, \& Shaver, 2008). Further, the Q-Sort measure used in the current study was validated against self-reported adult attachment measures (Chopik \& Edelstein, 2015). Thus, in the absence of further validation, it may be inappropriate to claim that we are reliably assessing attachment in younger participants. We decided to include all attachment data available for individuals 13 and older, given that attachment can be reliably measured by this age (Brenning et al., 2011; Feddern Donbaek \& Elklit, 2014; Wilkinson, 2011). Nevertheless, we acknowledge the heterotypic continuity of attachment and its resulting methodological challenges as a future direction in the Discussion. 